\title{
Entrevista
}

\section{Ana Zandwais entrevista o Professor Adail Sobral: sobre o fazer tradutório}

AZ. Em "Conversas com Tradutores" [Parábola Editorial, 2003; 2a ed.: 2007] refletes a respeito da condição e das ações do tradutor na atualidade, configurando o ato de traduzir como um ato essencialmente ético. Sob que aspectos, segundo tua ótica, o trabalho de traduzir intervém na realidade social e cultural como um ato ético?

AS. Num mundo sempre mais globalizado, a babélica tarefa do tradutor requer dele considerações éticas sempre mais amplas, que vão do conhecimento dos objetivos específicos dos clientes ou leitores quando ele traduz um dado texto ao impacto de uma dada tradução no mundo atual, passando pela "educação" do cliente ou leitores quanto à escolha do profissional tradutor e à avaliação da qualidade das traduções. Quem traduz tem de ser ético porque serve (legitimamente) a dois senhores, na qualidade de "parteiro" de sentidos fecundados numa dada língua e que nascem, ou emergem, em alguma outra.

A situação fica ainda mais complicada porque quem traduz está dilacerado entre duas exigências contraditórias, advindas de concepções essencialistas de tradução: de um lado, a de que respeite o "espírito" (e mesmo a "letra", ao menos em alguns de seus aspectos) da língua estrangeira, e não se importe com a língua não-estrangeira; do outro, que respeite o "espírito" (e mesmo a "letra", ao menos em alguns de seus aspectos) a língua não-estrangeira e não se importe com a língua estrangeira. O imperativo ético de sua tarefa impõe-lhe, em vez disso, respeitar, sem desprezar, esses dois "espíritos" e essas duas "letras". E deve fazê-lo sem deturpá-las, ainda que, humano que é, o tradutor possa enganar-se.

Outro espectro que ronda essa tarefa é a da equivalência entre termos das línguas entre as quais traduz. A ética requer que o profissional trabalhe não com termos e nem mesmo com textos apenas, mas com discursos, o que envolve, na verdade, ver a tradução como a restituição em outra língua de relações enunciativas criadas em uma dada língua. $O$ tradutor de certo modo tem o poder de deturpar valores, de impor interpretações, caso não tenha um comportamento ético. O tradutor não precisa ser fiel ao texto per se, materialmente falando, para ser fiel ao "original", porque importa criar, seja qual for o texto, efeitos de sentido correspondentes (melhor dizendo, co-respondentes, que respondem, replicam, dialogam) em outra língua.

O texto é o veículo de um discurso, e este é uma representação interessada do mundo (composta por uma descrição de um estado de coisas, no âmbito e regras de uso da linguagem, a partir de uma intencionalidade determinada pelo contexto). Logo, ser ético é ser fiel aos recursos de criação de sentido da língua de que se traduz e aos recursos de criação de sentidos da língua para língua para a qual se traduz. Nesse sentido, 
ser fiel ao "espírito" de que o texto é a "letra" pode implicar desrespeitar a "letra" do texto, que afinal é só o "veículo" do "espírito", embora só por meio dele possamos ter acesso a esse "espírito". Traduzir é encontrar meios numa língua de dizer o que se diz em outra. por isso exige ética.

Em seu labor, o tradutor tem de identificar, respeitar e reconstituir em outra língua a intencionalidade do autor lido e a especificidade do contexto de seus leitores (claro que na medida do humanamente possível, porque o sentido é algo que nunca se realiza por inteiro, restando sempre algo que não se consegue apreender). Os leitores da tradução leem o texto do tradutor, que tem o do autor estrangeiro como uma de suas bases, e não o autor. Como me perguntou um dos autores de quem traduzi alguns textos: "que imagem de mim estás criando no Brasil através das traduções?” Isso resume a meu ver a responsabilidade ética do tradutor como interface entre culturas: que imagem ele cria numa dada língua de um autor que escreveu em outra e que ele, tradutor, tornou acessível. O tradutor é na verdade um coautor, devendo evitar eticamente ser coator, impor-se ao autor ou impor-se aos leitores.

E assumir essa responsabilidade ética, sem criar álibis para si mesmo, mas com a certeza de que o erro é inevitável e até parte da condição humana, é a base do ato de interpretação legítima que é a tradução. Não criar álibis impede o tradutor de dizer "eu não sabia", mas não o impede de dizer "errei", e até o obriga a isso, se erros houver. Porque traduzir é sempre interpretar, legitimamente, ou seja, sem impor ao texto a traduzir as preferências ou ideias do tradutor.

O ato ético do tradutor é babélico: trata-se de evitar a "confusão" e abrir as portas "celestes" da compreensão, algo que está sujeito, como todo ato e qualquer ato humano, à incompreensão. Dos autores, dos editores, dos leitores, dos colegas tradutores... Traduzir é - deve ser! — um ato ético de criar efeitos de sentido vindos de uma língua em outra língua. Logo, traduzir exige - para resumir -- uma grande responsabilidade ética porque o discurso produzido pela tradução tem efeitos teóricos e práticos na realidade social e cultural ao criar (ou reconstituir, restituir) modos de ver o mundo, de valorar a realidade, ao estabelecer parâmetros de pensamento, ao conciliar e ao mesmo tempo por em confronto valores de duas culturas distintas.

AZ. 2. Quais os maiores desafios que os Cursos de formação de bacharéis em Letras com ênfase em tradução precisam enfrentar a fim de formar profissionais capazes de atender às múltiplas demandas do ofício da tradução?

AS. Do ponto de vista da formação, os cursos têm de considerar que traduzir difere de ensinar idiomas e devem oferecer um currículo adequado a essa tarefa, um currículo marcado pela concentração no desenvolvimento da capacidade de entender e explorar devidamente os recursos expressivos das línguas com que trabalha.

Os diferenciais do bom tradutor, ou tradutor competente, são: profissionalismo, para poder dedicar-se com seriedade a seu ofício; curiosidade intelectual, para sempre buscar uma solução melhor a partir de seu conhecimento de mundo; e humildade pessoal, para sempre duvidar de ter chegado ao melhor e para aceitar que por vezes a melhor solução é a menos pior - em vez de se perder em regras práticas vazias ou na busca de soluções mirabolantes.

Todo ato de tradução envolve a leitura de um texto numa dada língua que difere da leitura em geral porque é feita do ponto de vista de um profissional que, em vez de apenas entender o que lê ou responder/reagir ao que lê, deve enunciá-lo para outros 
interlocutores, tem de reconstituir/reconstruir/restituir o que lê em outra língua, e que, portanto, tem de penetrar em dois universos de discurso e colocá-los numa relação de interlocução, constituindo-se num mediador entre o autor do texto traduzido, que se dirige a um dado público que conhece, e o público do texto traduzido, ao qual o autor não pode dirigir-se diretamente. Logo, os cursos devem oferecer uma ampla formação de leitura crítica, uma espécie de formação em análise de discurso na qual o tradutor se torne qualificado para ler a forma do conteúdo e a forma da expressão, em vez de limitar-se seja à forma ou ao conteúdo isoladamente.

Como expliquei alhures, o tradutor precisa ter condições de entender:

a. Seu próprio perfil psico-social, uma vez que ele organiza os textos de uma maneira que afeta esses textos, nos termos de suas vivências, de sua experiência, do que julga ser tradução etc.;

b. o perfil psico-social do(s) público(s) da tradução, que vai/vão fazer sua leitura nos termos de sua situação de vida específica (do tipo de público que é/são), e não nos termos do tradutor;

c. a natureza específica da situação de interação entre os autores dos textos traduzidos e o público. E não só em geral — entre os "papéis sociais" do tradutor, do que se julga ser tradução etc. — como nos termos específicos do objetivo da tradução, do tipo de tradutor que ele é (especializado, técnico etc).

Assim, os cursos precisam promover enfaticamente o conhecimento da língua materna; a capacidade de mobilização do conhecimento de mundo e de áreas específicas a que os tradutores em formação possam desejar dedicar-se; o conhecimento de línguas estrangeiras (mesmo que o tradutor só vá trabalhar com uma); a capacidade de lidar com os dois sistemas sóciocognitivos distintos que são o par de línguas com que vai trabalhar.

De modo específico, os cursos devem promover o desenvolvimento das seguintes capacidades de adaptação cultural:

- EXPLICITAÇÃO - detalhar no texto-alvo ao menos parte do que é sugerido no texto-fonte, principalmente as especificidades do campo do saber e as referências culturais mais específicas.

- SIMPLIFICAÇÃO - reduzir o esforço de processamento do leitor do textoalvo para uma leitura mais fluida e uma melhor compreensão.

- NORMALIZAÇÃO - "Domesticar" em algum grau o tom do discurso do texto-fonte para torná-lo compreensível no texto-alvo, sem desfigurá-lo.

Devem recorrer para isso a um trabalho com:

- A consideração do contexto-alvo (público-alvo, local, tipo de discurso etc.) e sua relação com o contexto-fonte, em vez de se restringir ao texto.

- A ampla exploração das possibilidades idiomáticas da língua-alvo em sua relação com as da língua-fonte na produção de um novo texto.

- O uso hábil de recursos como reestruturação de trechos, notas, colchetes e interpolações nos casos de maior necessidade de adaptação tendo em vista as necessidades do público-alvo. 


\section{Conexão Letras}

Pois a meta final da formação acadêmica dos tradutores deve ser desenvolver a capacidade de negociação, isto é, saber colocar-se a meio caminho entre o texto-fonte e o textoalvo, respeitando as duas culturas. Essa é uma capacidade que requer maior esforço de adaptação cultural e que produz os resultados esperados da tarefa de mediação cultural que é traduzir. Porque traduzir é, mais do que uma tarefa de transposição entre línguas, a releitura negociada de uma dada cultura com os olhos de outra, algo que toda boa formação tem de levar em conta.

AZ. 3. Em que aspectos, no processo de formação do perfil de tradutores, entendes que a Universidade precisa investir com mais ênfase, maior determinação?

AS. Afora os aspectos mencionados na pergunta dois, que estou relacionando com esta, a Universidade deve preocupar-se em formar o tradutor para ser um mediador entre culturas, uma vez que todo ato de tradução envolve o contato, o confronto, a negociação, entre duas culturas (e mesmo entre os vários segmentos sociais interculturais tanto da língua de partida como da língua de chegada.

É preciso que a Universidade enfatize que traduzir é

a. Uma atividade em que é vital entender o que é expresso numa língua, considerando quem diz o que a quem, como, onde, quando e, principalmente, com que projeto de dizer, no âmbito de uma dada cultura, e exprimi-lo de modo a ser entendido em outra língua, levando em conta quem diz o que a quem, como, onde, quando e, principalmente, com que projeto de dizer, no âmbito de outra cultura. $O$ público da língua de partida não é o mesmo público da língua de chegada.

b. Uma atividade que mantém o "mesmo", que é o dizer, o como foi dito e o querer dizer do texto de partida, que existem numa dada cultura, e também o altera no texto de chegada, porque diz o "mesmo" em outra língua, a outros sujeitos, de outra cultura que tem seus próprios modos de dizer, de como dizer e de querer dizer. Uma atividade que implica colocar culturas em contato com o mínimo de conflito.

c. Uma atividade que requer desenvolver habilidades de compreensão e de expressão que compatibilizem as formas culturalmente estabelecidas de dizer na língua de partida e na língua de chegada, bem como a capacidade de usar recursos que permitam ao leitor melhor entender o que disse o autor com o menor esforço possível, o que implica produzir um texto próximo de um texto escrito na língua-alvo. 